\title{
Pasireotide-LAR in acromegaly patients treated with a combination therapy: a real-life study
}

\author{
Hélène Lasolle ${ }^{1,2,3}$, Amandine Ferriere ${ }^{4,5}$, Alexandre Vasiljevic ${ }^{2,3,6}$, Sandrine Eimer ${ }^{5,7}$, Marie-Laure Nunes ${ }^{4}$ and \\ Antoine Tabarin ${ }^{4,5}$ \\ ${ }^{1}$ Fédération d’Endocrinologie, Centre de Référence Maladies Rares Hypophysaires HYPO, Groupement Hospitalier Est, Hospices Civils de Lyon, \\ Bron, France \\ ${ }^{2}$ Faculté de Médecine Lyon Est, Université Lyon 1, Lyon, France \\ 3INSERM U1052; CNRS UMR5286; Cancer Research Centre of Lyon, Lyon, France \\ ${ }^{4}$ Service d'endocrinologie, diabète et nutrition, Hôpital Haut Lévêque, CHU de Bordeaux, Bordeaux, France \\ ${ }^{5}$ UFR Sciences médicales, Université de Bordeaux, Bordeaux, France \\ ${ }^{6}$ Centre de Pathologie et de Neuropathologie Est, Groupement Hospitalier Est, Hospices Civils de Lyon, Bron, France \\ ${ }^{7}$ Service d'anatomo-pathologie, Hopital Pellegrin, CHU de Bordeaux, Bordeaux, France
}

Correspondence should be addressed to A Tabarin: Antoine.tabarin@chu-bordeaux.fr

\begin{abstract}
Purpose: Little data are available regarding the safety and efficacy of switching to Pasireotide-LAR monotherapy in acromegaly patients with partial resistance to firstgeneration somatostatin agonists (1gSRL) who require combination treatment with cabergoline or pegvisomant.

Method: In this monocentric prospective study within a tertiary university hospital, 15 consecutive acromegalic adults partially resistant to $1 \mathrm{gSRL}$ treated with octreotide LAR or lanreotide SR, and cabergoline $(n=4,3.5 \mathrm{mg} /$ week) or pegvisomant $(n=11$, median dose $100 \mathrm{mg} /$ week), were switched to Pasireotide-LAR ( 8 with $40 \mathrm{mg} / \mathrm{month} ; 7$ with $60 \mathrm{mg} / \mathrm{month})$. Immunohistochemical expression level of SSTR5 and the granulation pattern of nine somatotroph adenomas were retrospectively determined to test for a correlation with the therapeutic efficacy of Pasireotide-LAR.

Results: Median IGF-1 concentration at the first evaluation (median 3 months) was similar to baseline (1.0 vs $1.1 \mathrm{ULN}$ ). 11/15 patients had IGF-1 levels $\leq 1.3$ ULN before and after the switch but individual changes were variable. Hyperglycemia was frequent and greater in diabetic patients. 7/15 patients stopped Pasireotide-LAR due to lack of control of IGF-1 or intolerance. 8/15 patients received Pasireotide-LAR for a median of 29 months with IGF-1 levels $\leq 1.3$ ULN and acceptable glucose tolerance (median HbA1c $6.1 \%$ ). Two patients required initiation of oral antidiabetic treatment. The intensity of SSTR5 expression and the granulation pattern of adenomas were of limited value for the prediction of Pasireotide-LAR effectiveness.

Conclusion: Pasireotide-LAR may represent a suitable therapeutic alternative in a subset of acromegalic patients requiring combination therapy involving a $1 \mathrm{gSRL}$
\end{abstract}

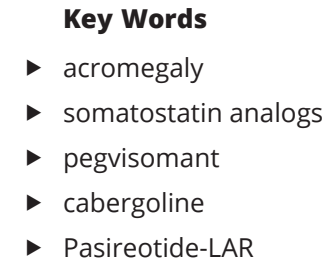

Endocrine Connections (2019) 8, 1383-1394

\section{Introduction}

Acromegaly is predominantly caused by a growth hormone (GH)-secreting pituitary adenoma resulting in excessive insulin-like growth factor-I (IGF-I) secretion that is responsible for numerous co-morbidities, reduced quality of life and increased mortality rate (1). Surgical excision of the pituitary adenoma is the only curative treatment for acromegaly, but its effectiveness is limited depending on the size and extension of the pituitary https://ec.bioscientifica.com

https://doi.org/10.1530/EC-19-0332

(c) 2019 The authors Published by Bioscientifica Ltd

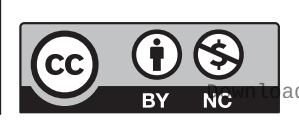

This work is licensed under a Creative Commons Attribution-NonCommercial 4.0 International License. ded from Bioscientifica.com at 04/26/2023 10:24:12AM 
adenoma, as well as the expertise of the surgeon (2). Medical management of acromegaly is used when surgery fails to control the disease or when surgery cannot be performed (3). First-generation long-acting somatostatin analogs (1gSRL) (octreotide LAR and lanreotide Autogel) are the most widely used first-line medical treatments and induce a significant decrease in GH/IGF-1 levels in a majority of patients. IGF-1 normalization is highly variable across studies ranging from 23 to $98 \%$ of patients (4). The GH receptor antagonist, pegvisomant (PEG), is a second-line treatment which normalizes IGF-1 plasma levels in $60-70 \%$ (5) of patients in follow-up registries and up to $97 \%$ in single-center series (6). The dopamine D2-receptor agonist, cabergoline, is an alternative to 1 GSSA, normalizing IGF-1 plasma level in 30\% of patients, especially when IGF-1 is moderately increased (7). Combination of 1gSRL and PEG is an increasingly prescribed alternative, in patients with partial resistance to 1gSRL (8) showing high efficacy with the added benefit of lowering the required PEG dose, thus reducing the frequency of injections from a daily to a weekly regimen and lowering treatment costs. Combination of 1gSRL with cabergoline is a less frequently used alternative in these patients.

Pasireotide-LAR is a multireceptor-targeted somatostatin analog with superior clinical efficacy over octreotide-LAR (9) that can control GH and IGF-1 concentrations in patients resistant to 1gSRL (10). Consequently, it is approved for treatment of acromegaly where surgery is not an option (or was not curative) and where it is not controlled by treatment with a 1gSRL. Pasireotide-LAR could therefore be an alternative to 1gSRL+PEG and 1gSRL+cabergoline combination therapies. Two previously published studies have examined this possibility. The largest study used a relatively complex prospective clinical research protocol involving a run-in phase with a $50 \%$ reduction dose of PEG prior to the start of Pasireotide-LAR and additional titration of the PEG dosage to achieve IGF-1 control and, when possible, Pasireotide-LAR monotherapy (11). Shimon et al. published a study which was more consistent with 'real-life' practice and included nine and four patients who were previously treated with either an association of 1gSRL and PEG or cabergoline respectively (12). However, this study was retrospective and multicentric, involving various initiation doses and adjustments of Pasireotide-LAR as well as various laboratories for $\mathrm{GH}$ and IGF-1 measurement. Recent recommendations for the use of Pasireotide LAR have been published by one expert group mentioned above (13). However, given the scarcity of studies, the effectiveness and safety of the switch to Pasireotide-LAR in acromegaly patients partially responsive to $1 \mathrm{gSRL}$ and treated with a combination therapy still warrants complementary studies.

We report herein the results of a single-center 'real life' study evaluating the effectiveness and safety of switching consecutively 15 acromegalic patients, from a combination therapy including 1gSRL to Pasireotide-LAR therapy. In an effort to identify biomarkers of treatment outcome, we also examined whether the in vivo efficacy of Pasireotide-LAR correlated with expression levels of SSTR5 and the granulation pattern of the adenomas.

\section{Materials and methods}

\section{Study design}

From December 2015 to August 2017, 15 acromegalic patients treated with a medical combination therapy including a 1gSRL and who were seen as part of their usual follow-up were prospectively proposed to be switched to monotherapy with Pasireotide-LAR. A consent to care was obtained in all patients for the change of treatment of acromegaly after full explanation of the purpose and nature of all procedures used. The data were collected under conditions of regular clinical care and were anonymised and protected for the study. The study was approved by the Ethical Committee of the Bordeaux University Hospital.

Prior to the switch, all patients underwent the following standard evaluations of care: a clinical evaluation using a non-validated standardized 20-point score that is used in our department (4 points for asthenia, headache, sweating, arthralgia and swelling, respectively); a centralized IGF-1 assay; pituitary MRI (Coronal, sagittal T1 and T2 sequences, with and without gadolinium); measurement of hemoglobin A1C (HbA1c) and fasting blood glucose (FBG). Patients were considered diabetic if they were being treated for diabetes and/or when FBG was $\geq 126 \mathrm{mg} / \mathrm{dL}$ and/or $\mathrm{HbA} 1 \mathrm{c} \geq 6.5 \%$. Patients were considered glucose intolerant when FBG was $\geq 100 \mathrm{mg} / \mathrm{dL}$ and $\leq 125 \mathrm{mg} / \mathrm{L}$ and/or $\mathrm{HbA} 1 \mathrm{C}$ was $>5.7$ and $\leq 6.4 \%$. All patients underwent a dietary evaluation and received dietary advice and education about frequent measurement of capillary glycemia during the first 3 months of treatment. Patients were encouraged to attend for outpatient consultation in the event of a major increase in capillary glycemia.

The first evaluation was performed after approximately 3 months of treatment and during the week before the next

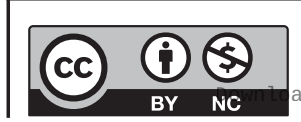

This work is licensed under a Creative Commons Attribution-NonCommercial 4.0 International License. ded from Bioscientifica.com at 04/26/2023 10:24:12AM 
planned administration of Pasireotide-LAR. It included the same assessments as the baseline evaluation with the addition of 1-3 measurements of plasma GH. A variation in the clinical score $\geq 2$ was considered as significant.

Depending on the results of this evaluation, Pasireotide-LAR was either continued or interrupted. If the treatment was continued, patients were monitored at roughly 3-monthly intervals. A pituitary MRI was scheduled after the third month of treatment. Evaluation of the tumor height on MRI scans, performed before and after the switch, was retrospectively evaluated by a single experienced physician (A.T.) who was blinded to the identity and previous treatment of patients.

\section{Immunohistochemistry}

Formalin-fixed paraffin-embedded tumoral tissue was available for nine patients. Immunohistochemical (IHC) analysis was performed on $4 \mu \mathrm{m}$ sections using the BenchMark ${ }^{\circledR}$ ULTRA automated immunostainer (Ventana Medical Systems Inc, Tucson, AZ, USA). The primary antibodies used were against SSTR2 (rabbit monoclonal, clone UMB-1, 1:4000, Abcam), SSTR5 (rabbit monoclonal, clone UMB-4, 1:250, Abcam), and cytokeratin 18 (mouse monoclonal, clone DC10, 1:50, Dako). Bound antibodies were detected using a Ventana kit incorporating diaminobenzidine (DAB) as the color reaction (ultraView Universal DAB Detection Kit). Additional amplification was used for the SSTR5 immunostaining.

SSTR5 membranous immuno-positivity was evaluated by a semi-quantitative immunoreactive score (IRS) (14). This score, ranging from 0 to 12 , is the product of the proportion of immunoreactive cells (0: $0 \% ; 1: 1-10 \% ; 2: 11-50 \%$; $3: 51-79 \%$; and $4: \geq 80 \%)$ and the staining intensity (0: no staining; 1 : mild; 2 : moderate; and 3: strong). We considered the staining as being negative where IRS was 0 and 1 , weakly positive when IRS scores were 2 and 3, moderately positive for IRSs $4-8$, and strongly positive for IRSs $>8$.

The pattern of cytokeratin 18 immunoexpression was used to classify somatotroph adenomas into sparsely or densely granulated adenomas. Adenomas with a 'transitional' distribution were considered as densely granulated adenomas (15).

Histopathological analyses were performed by an experienced pathologist in the field (A.V.).

\section{Statistical analysis}

All quantitative data are presented using median, minimum and maximum. Pre- and post-switch quantitative data were compared using a paired Wilcoxon rank test. Significance was defined as a $P$ value of less than 0.05 .

\section{Assays}

GH and IGF-1 were assayed using LIAISON XL (Diasorin) immunoassay. For $\mathrm{GH}$, coefficient of variation (CV) was 6.7 and $6.3 \%$ at 3.69 and $19.3 \mathrm{ng} / \mathrm{mL}$, respectively; for IGF-1, CV was 10.4 and $10.2 \%$ at 97.5 and $389 \mathrm{ng} / \mathrm{mL}$, respectively. Results are expressed relative to sex and age upper limits of the normal range (ULN). Normal ranges of IGF-1 were taken from the 'Varieté' study (16).

\section{Patients}

Fifteen patients (10 women, 5 men) aged 50 years (range 27-67) were included. The age at diagnosis was 38 years (16-61), and IGF-1 and basal GH at diagnosis were 3.2 ULN (1.7-5.4) and $18.6 \mathrm{ng} / \mathrm{mL}(3.2-162)$, respectively. All but one patient had a macroadenoma. One 29-year-old patient had germinal AIP mutation ( $\mathrm{n}^{\circ} 4$, Table 1$)$.

Fourteen of 15 patients underwent surgical debulking of the pituitary adenoma and 13 of these 14 patients were treated with 1gSRL prior to surgery. Additionally, four patients received post-operative radiotherapy 2.8 , 5.8, 8.1 and 14.1 years before Pasireotide-LAR initiation. All patients were treated post-operatively with 1gSRL (somatuline autogel $(120 \mathrm{mg} / \mathrm{month}, n=7)$ or octreotide LAR $(30 \mathrm{mg} / \mathrm{month}, n=7))$. None of the patients showed normalization of IGF-1 levels. The maximal IGF-1 decrease during 1gSRL ranged from 39 to $50 \%$ and the median IGF-1 level prior to the combination therapy was 1.7 ULN (1.4-3.5). Consequently, the patients were treated with an association of 1gSRL and cabergoline (3.5 mg/week for four patients) or PEG $(100 \mathrm{mg} /$ week, (40-200) for 11 patients) (see Table 1). Pasireotide-LAR was introduced after 39 months (1.5-164) of treatment with the combination therapy. The first injection was performed at the time usually scheduled for the injection of the 1gSRL and patients simultaneously interrupted their intake of cabergoline and injections of PEG.

The median clinical score before the switch was $3 / 20$ $(0-12)$ and median plasma IGF-1 level was 1.0 ULN (0.4-4.1). The IGF-1 level was considered as controlled ( $\leq 1.3$ ULN) in 11 patients, was $>1.3$ ULN and $\leq 2.0$ ULN in 2 patients and $>2$ ULN in 2 patients. IGF-1 levels in patients receiving a 1gSRL and PEG combination tended to be lower than those in patients receiving 1gSRL and cabergoline in combination: $0.9(0.4-3.3)$ vs 1.5 (1.0-4) ULN, 
党

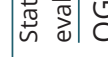

है|

ড|

这全

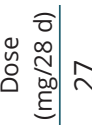

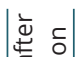

I

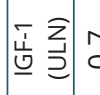

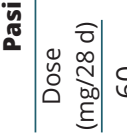

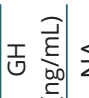

获

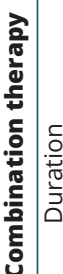

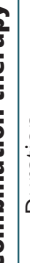

เ

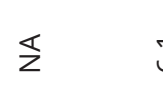

$\stackrel{\sim}{\square} \quad$

우

8

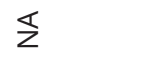

$\S$

$\S$

$\S$

$\stackrel{0}{\circ} \quad \stackrel{\infty}{0} \quad \stackrel{9}{0}$

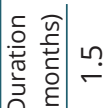

ஸ்

$\bar{m}$

$\stackrel{\sim}{\stackrel{+}{*}}$

in

$\stackrel{n}{6}$

৩

৩

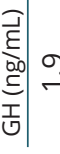

$\begin{array}{ll}0 & 0 \\ \text { 의 } & \text { ㅇ }\end{array}$

○

¿

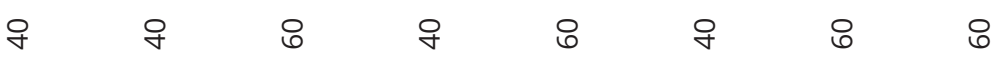

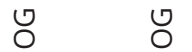

৩ั

$\check{0} \quad \stackrel{\infty}{0} \quad \stackrel{+}{\lessgtr}$

(2)

\section{○}

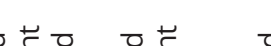

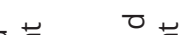

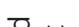

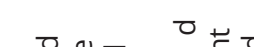

离

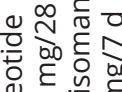

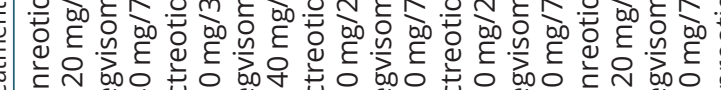

常|

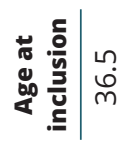

융

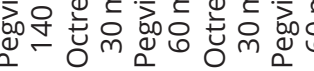

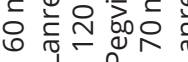

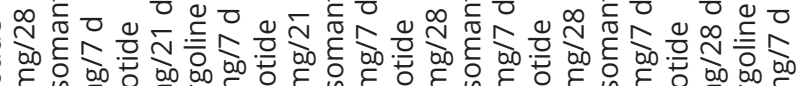

ह O a

等

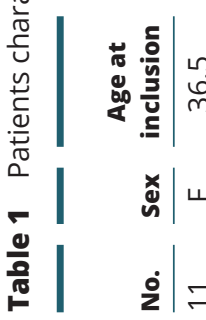

$\stackrel{m}{\text { nु }} \stackrel{\bar{\infty}}{m}$

$\bar{\infty} \quad \stackrel{m}{\sigma}$

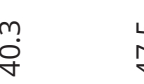

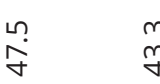

$\stackrel{m}{m} \quad \stackrel{o}{q} \quad \stackrel{\infty}{q}$

in

$\stackrel{0}{6}$

$\stackrel{m}{\frac{m}{i}}$

กั่

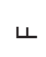

ч

$\Sigma$

I

เก

6

$\Lambda$

$\infty$

a

$ㅇ$ 


\begin{tabular}{l} 
respectively $(P$ value $=0.06)$. As most of the patients were \\
treated with PEG, plasma GH concentrations prior to the \\
switch were not considered (Table 1$)$. \\
The median size of pituitary adenoma remnants was \\
$9.3 \mathrm{~mm}(5-17)$ in 12 patients and it was non-measurable \\
in two patients. \\
Median HbA1c was $5.8 \%(5.3-7.2)$ and median fasting \\
glycemia $100 \mathrm{mg} / \mathrm{dL}(0.9-1.8)$. Four patients had normal \\
glucose tolerance, six had pre-diabetes and five patients \\
were diabetic (see Table 2$)$. Among five diabetic patients, \\
\hdashline
\end{tabular}

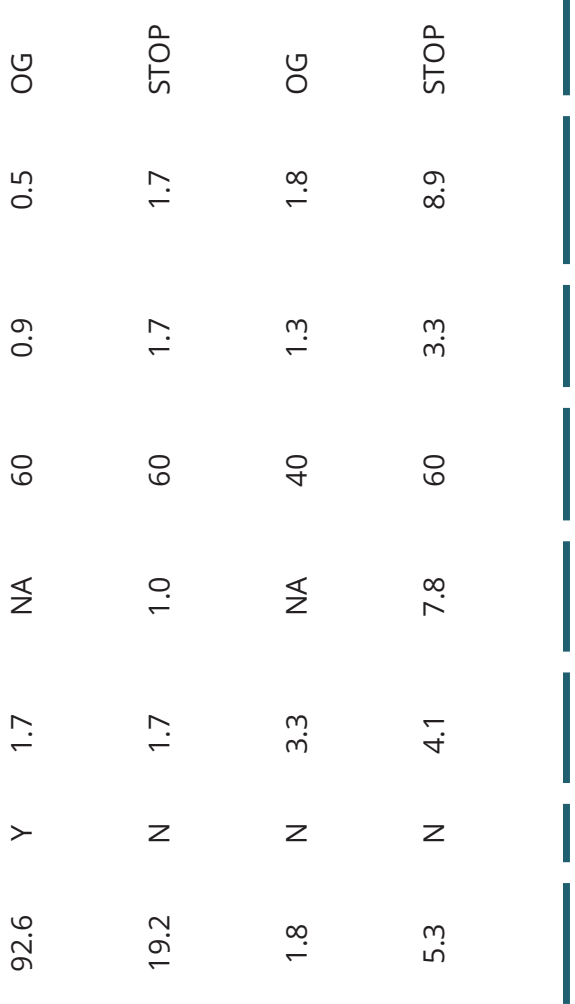

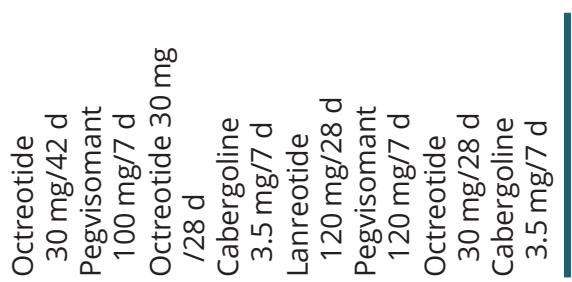

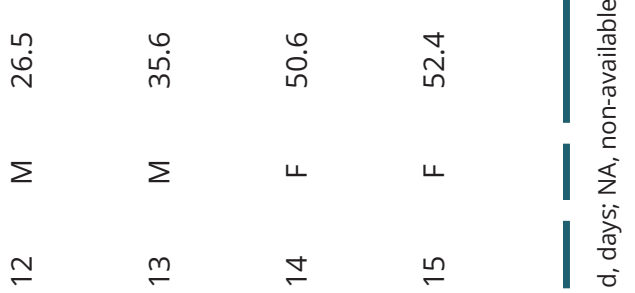

https://ec.bioscientifica.com https://doi.org/10.1530/EC-19-0332 (c) 2019 The authors Published by Bioscientifica Ltd

\section{Results}

\section{First clinical evaluation following the switch to Pasireotide-LAR-treatment}

The initial monthly dosage was randomly assigned except for diabetic patients who received $40 \mathrm{mg} / \mathrm{month}$. Seven patients started with $60 \mathrm{mg} / \mathrm{month}$ and 8 with $40 \mathrm{mg} / \mathrm{month}$. The first evaluation was obtained at 3.0 months (2.0-6.5) after 2 to 6 injections of Pasireotide-LAR (Table 1 and Fig. 1).

Median clinical score was $1.5(0-3)$ and was similar to baseline values $(P=0.30)$. Most patients had identical scores (variation $\leq 1$ point). Four patients improved their score (a decrease of $2-5$ points), two of these presented a concomitant IGF-1 decrease and two a stable IGF-1 level. The improvement of the score mainly related to asthenia. One patient had a 2 points worsening of their score contrasting with a significant IGF-1 decrease from 3.3 to $1.27 \operatorname{ULN}(\mathrm{n}, 14$, Table 1).

Median IGF-1 at the first evaluation was 1.0 ULN (0.5-3.3), similar to that measured prior to the switch (1.1 ULN (0.4-4.1); $P=0.49)$. Median GH was $1.54 \mathrm{ng} / \mathrm{mL}$ $(0.14-8.9)(n=12)$. Eleven of 15 patients had acceptable IGF-1 levels $\leq 1.3$ ULN (0.5-1.3) using a monthly dose of Pasireotide-LAR of $40 \mathrm{mg}$ in six patients and $60 \mathrm{mg}$ in five patients. Prior to the switch, plasma IGF- 1 was $\leq 1.3$ in nine patients, $>1.3$ and $\leq 2$ in one patient and $>2$ in one of these 11 patients, respectively. Three of 15 patients had IGF-1 levels $>1.3$ ULN and $\leq 2(1.5-1.8)$ using a monthly dose of Pasireotide-LAR of $40 \mathrm{mg}$ in two patients and $60 \mathrm{mg}$ in one patient. Prior to the switch, two of these three patients had IGF-1 $\leq .3$ ULN and one had IGF-1 $>1.3$ and $\leq 2$. One of the 15 patients presented an IGF-1 level $>2$ ULN (3.3) with a monthly dose of Pasireotide- 

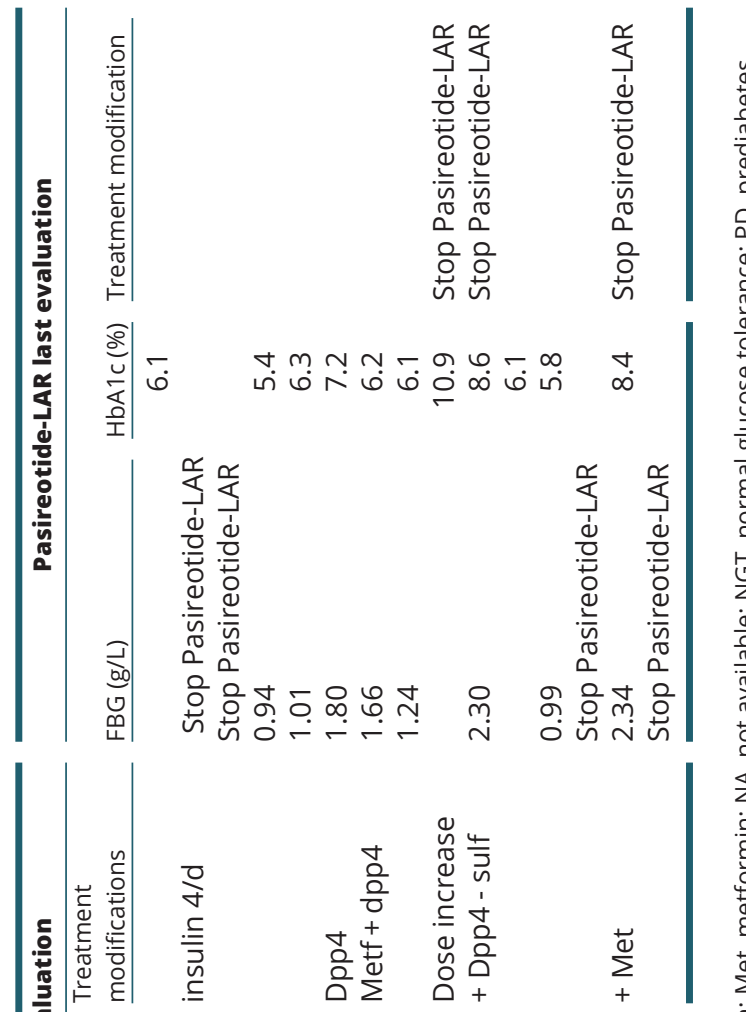

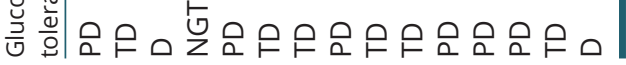

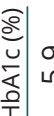
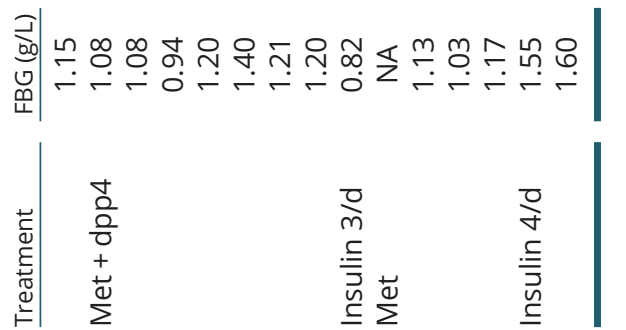

\section{$\frac{\pi}{4}$}

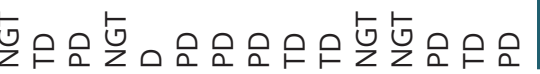

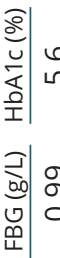

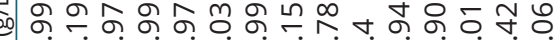

$\dot{\mathbf{s}}$

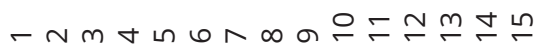

LAR of $60 \mathrm{mg}$. His IGF-1 level prior to the switch was 4.1 ULN (Table 1).

Overall and, in comparison with the combination therapy, 7 vs 6 patients had an IGF- $1<1$ ULN, four vs five patients had IGF- $1 \geq 1$ ULN and $\leq 1.3$ and 4 vs 4 patients had and IGF-1 $>1.3$ ULN (Fig. 1). Using the strict criteria of $\mathrm{GH} \leq 1 \mathrm{ng} / \mathrm{mL}$ with IGF-1 $\leq 1 \mathrm{ULN}, 3 / 15$ patients were controlled with Pasireotide-LAR. The median IGF-1 level prior to the switch tended to be lower in patients with acceptable IGF-1 control ( $\leq 1.3$ ULN) than in those with IGF-1 >1.3 ULN during Pasireotide-LAR therapy: 0.9 $(0.4-1.7)$ vs $1.5(0.6-4.1) ; P=0.06$. Similarly, in patients treated with a combination therapy involving PEG, the PEG weekly dose was lower in patients with acceptable IGF-1 control $(\leq 1.3$ ULN) than in those with IGF-1 $>1.3$ : $75 \mathrm{mg}$ (40-105) vs 140 (120-200); $P<0.02$.

Digestive tolerance was found to be acceptable. No abnormality of hepatic biochemistry occurred. One patient complained of alopecia and one of dizziness.

A significant increase in FBG was observed compared to baseline levels: $117 \mathrm{mg} / \mathrm{dL}$ (82-160) vs $101 \mathrm{mg} / \mathrm{dL}$ (90-178) respectively, $P<0.04$. Similar findings were observed for HbA1C: $6.3 \%(5.4-8.4)$ vs $5.8 \%$ (5.3-7.2), $P<0.01$. Significant therapeutic modifications in antidiabetic therapy were carried out in the four diabetic patients, including a switch from oral therapy to insulin injections in one. FBG and HbA1C remained stable in the remaining diabetic patient treated with diet only. Four of the five patients with pre-diabetes became diabetic, with a mild increase in $\mathrm{HbA} 1 \mathrm{C}$ in two of these, while a pharmacological treatment was required in two patients. Four of the five patients with normal glucose tolerance became prediabetic with a mild increase in HbA1C (from 5.6 (5.4-5.6) to 5.9\% (5.9-6.0)). Overall, a pharmacological anti-diabetic intervention was given in 6/15 patients, as early as 15 days after the beginning of Pasireotide-LAR treatment (Table 2).

The treatment with Pasireotide-LAR was interrupted at the first evaluation in 4/15 patients in view of a lack of control of IGF-1 in two patients treated with 60mg/month ( $n, 13$ and $n$, 15; Table 1$)$; dizziness in one patient treated with $40 \mathrm{mg} / \mathrm{month}$ despite controlled IGF-1 ( $n, 3$; Table 1$)$ and due to association of major hyperglycemia $(300 \mathrm{mg} / \mathrm{dL})$ requiring initiation of insulin treatment and lack of control of IGF-1 ( $n, 2$ : Table 1$)$ in one patient treated with $60 \mathrm{mg} / \mathrm{month}$.

Eleven patients initially treated with $40 \mathrm{mg} / \mathrm{month}$ $(n=7)$ and $60 \mathrm{mg} / \mathrm{month}(n=4)$ continued to be treated with Pasireotide-LAR. The dosage was increased from 40 to $60 \mathrm{mg} / \mathrm{month}$ in three patients who had IGF-1 levels 1.3, 1.3 and 1.8 ULN at the first evaluation. https://ec.bioscientifica.com https://doi.org/10.1530/EC-19-0332 (c) 2019 The authors Published by Bioscientifica Ltd
This work is licensed under a Creative Commons Attribution-NonCommercial 4.0 International License. ded from Bioscientifica.com at $04 / 26 / 2023$ 10:24:12AM
via free access 
Plasma IGF-1 concentration

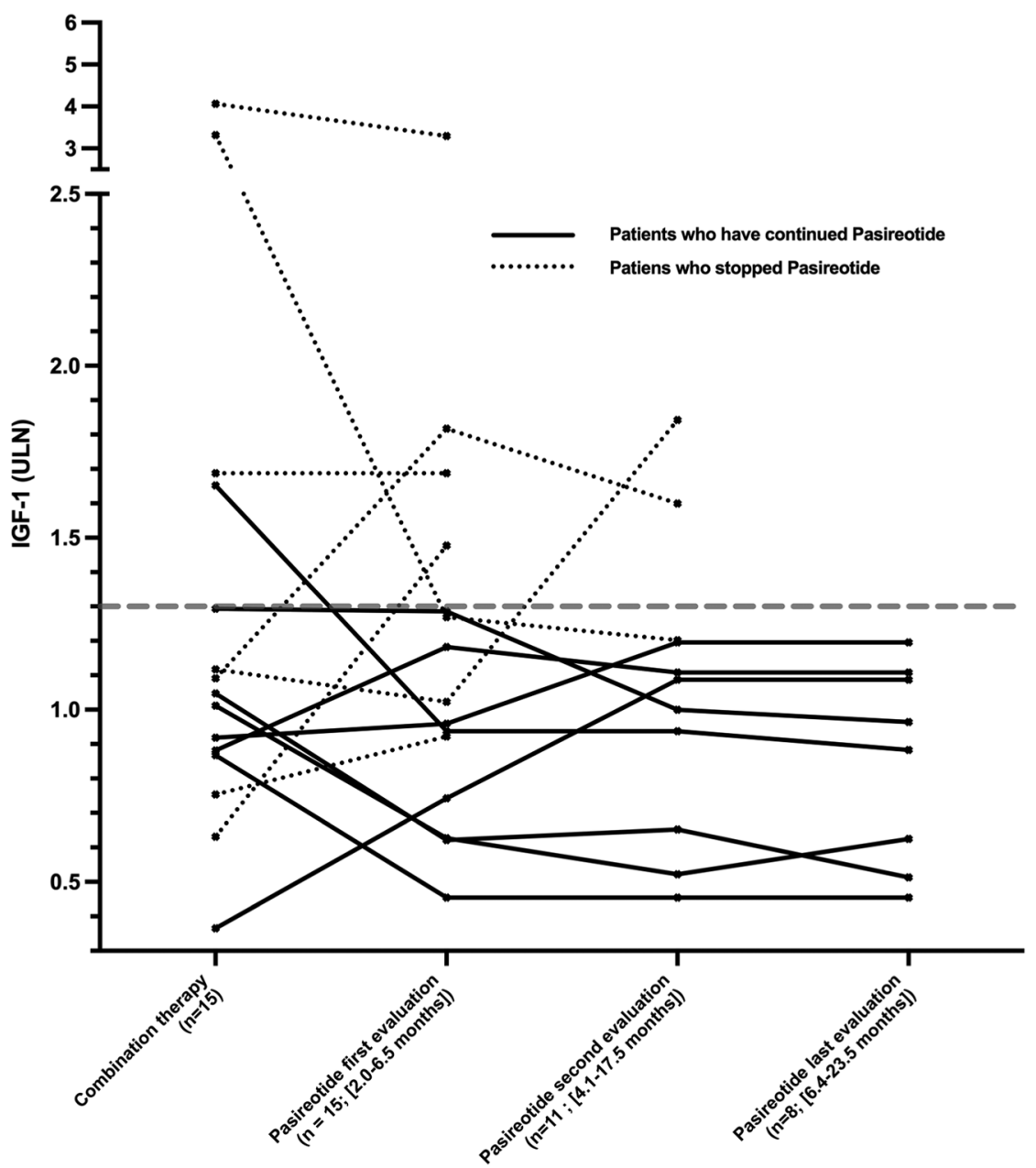

\section{Figure 1}

Evolution of IGF-1 results (expressed relatively to the upper limit normal of the assay ULN) for each patient during combination therapy and at subsequent evaluations (ev) following the switch to Pasireotide-LAR. The broken line is set at the upper limit of 'controlled' IGF-1 levels (1.3 ULN).
Final clinical evaluation following the switch to Pasireotide-LAR-treatment

Three of the 11 patients stopped Pasireotide-LAR after 6, 6 and 18 months of treatment: 2 patients $(n, 10$ and 9, Table 1) treated with 40 and $60 \mathrm{mg} / \mathrm{month}$ had persistently increased IGF-1 levels (1.6 and 1.8 ULN) and had unacceptable hyperglycemia (HbA1c 8.6 and $10.9 \%$ ) despite intensification of anti-diabetic treatment. Another patient $(n, 14$, Table 1$)$ treated with $60 \mathrm{mg} / \mathrm{month}$ had a controlled IGF-1 (0.6 ULN compared to 3.3 ULN during the combination therapy) but also developed major hyperglycemia (HbA1c 11\%) despite anti-diabetic treatment (Table 1 and Fig. 1).

IGF-1 levels following the increase in Pasireotide-LAR dosage in three patients $(n, 10,11$ and 14; Table 1$)$ changed from $1.8,1.3$ and 1.3 to $1.6,0.9$ and 1.2 ULN, respectively. However, two of these three ( $n, 10$ and 14) had to cease treatment due to hyperglycemia (HbA1c increased from 7.6 and $7.1 \%$ to 8.6 and $8.4 \%$ respectively).
Eight patients were still being treated with Pasireotide-LAR after 29 (17-34) months. The monthly Pasireotide-LAR dosage was $60 \mathrm{mg}$ and $40 \mathrm{mg}$ in five and three patients, respectively. Median IGF-1 was 0.8 ULN (0.5-1.2). Median GH was $0.9 \mathrm{ng} / \mathrm{mL}$ (0.2-7.3). Using the strict criteria of $\mathrm{GH} \leq 1 \mathrm{ng} / \mathrm{mL}$ plus IGF-1 $\leq 1 \mathrm{ULN}$, $3 / 8$ patients were controlled. As compared to the results obtained during combination therapy, five patients vs four had IGF-1 $<1.0 \mathrm{ULN}$, three patients vs three had $1.0<$ IGF- $1 \leq 1.3$ and 0 patients vs 1 had IGF- $1>1.3$ ULN (Fig. 1).

Median HbA1c in these eight patients was 6.1\% (5.4-7.2) and median FBG was $120 \mathrm{mg} / \mathrm{dL}$ (90-181). Two of these were pre-diabetic prior to the switch and required an antidiabetic treatment with a dpp4-inhibitor ( $n, 6$, last HbA1C 7.2\%), and metformin plus a ddp4-inhibitor $(n, 7$, last HbA1c 6.2\%). The six remaining patients $(n$, $1,4,11$ and 12 with normal glucose tolerance, $n, 8$ with prediabetes and $n, 5$ with non-treated diabetes prior

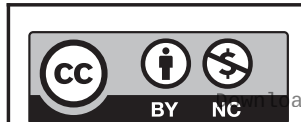

This work is licensed under a Creative Commons Attribution-NonCommercial 4.0 International License. ded from Bioscientifica.com at 04/26/2023 10:24:12AM via free access 

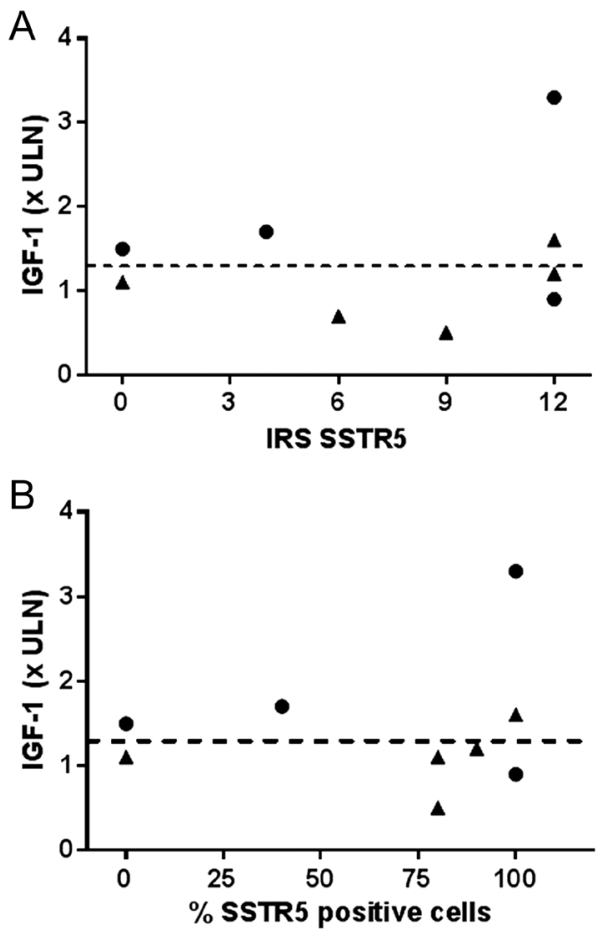

Figure 2

IGF-1 during Pasireotide-LAR treatment (1st evaluation) in relation with SSTR5 expression (A: IRS score, B: number of SSTR5-positive cells) and cytokeratin 18 expression (closed circles: densely granulated, closed triangles : sparsely granulated).

to the switch) achieved acceptable glycemic control $(\mathrm{HbA} 1 \mathrm{C}=6.1 \%)$ with only lifestyle advice.

\section{Pituitary MRI evaluation following the switch}

MRI evaluation performed before the switch and after 8 months (4-14 months) of Pasireotide-LAR treatment was available for 11 patients. Tumor residue was nonmeasurable in two patients, and the median height did not differ between before and after the introduction of Pasireotide-LAR in the nine remaining patients: $9 \mathrm{~mm}$ (5-18) vs $8 \mathrm{~mm}(4-12)$, respectively $(P=0.44)$. At the individual level, one patient presented a significant reduction in tumor size from 6.4 to $3.7 \mathrm{~mm}$ during Pasireotide-LAR treatment, while IGF-1 levels were stable. No change in the intensity of the signal was visible in T2-weighted sequences.

\section{Immunohistochemical studies}

Retrospective histological analysis of somatotroph adenomas was available for nine patients. All but one had been treated with 1gSRL before surgery. Five tumors were classified as densely granulated (DG) and four as sparsely granulated (SG). There was no obvious association between the IRS score for SSTR5 and the IGF-1 response to Pasireotide-LAR (Fig. 2). This is illustrated by the IRS in patients with controlled IGF-1 ( $<1.3$ ULN) which was evenly distributed from 0 to the maximal score of 12 . In the same vein, one patient with an IGF-1 value of 3.3 ULN during Pasireotide-LAR treatment had a maximal score IRS of 12. Assessment of the percentage of immunoreactive cells for SSTR5 regardless of the intensity of staining, a semi-quantitative and somewhat subjective factor, did not change the results of the analysis. There was a trend toward an association between the IGF-1 response to PasireotideLAR and cytokeratin expression (characterizing the granulation phenotype), since three of four patients with sparsely granulated adenomas had controlled IGF-1 versus two of five patients with densely granulated adenomas. Illustrative cases are provided in Fig. 3.

\section{Discussion}

Although involving a small cohort, this single-center prospective study is one of few that have evaluated the tolerance and efficacy of the substitution of PasireotideLAR to a combination therapy involving a 1gSRL in conditions of 'real-life' clinical practice. Additionally, we have attempted to correlate the response to PasireotideLAR treatment with the granulation status and immunohistochemical expression of SSTR5 in previously resected somatotroph adenomas.

Overall, Pasireotide-LAR was able to control IGF-1 at an acceptable level $(\leq 1.3$ ULN) with an acceptable tolerance in $8 / 15$, while the combination therapy had to be resumed in 7/15 patients due to inefficacy or intolerance. The immunohistochemical expression of SSTR5 was not found to be correlated with IGF-1 control.

In our study, the overall number of patients controlled with Pasireotide-LAR and median IGF-1 levels were comparable to that obtained with combination therapy. The changes in clinical scores were mild, unsurprisingly, since baseline scores were rather low, as expected since 13/15 acromegalic patients had roughly controlled IGF-1. However, there were marked individual differences in the IGF-1 response to the two therapeutic strategies: while 9/15 patients had similar results in terms of IGF-1 control, three showed improvement during PasireotideLAR therapy while three showed an increase.

The individual response to Pasireotide-LAR was therefore heterogeneous, similar to a previous study of a small cohort of patients treated with 1gSRL and PEG

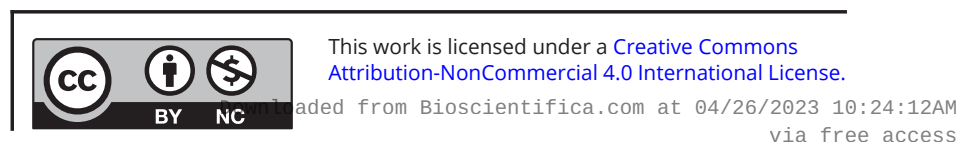



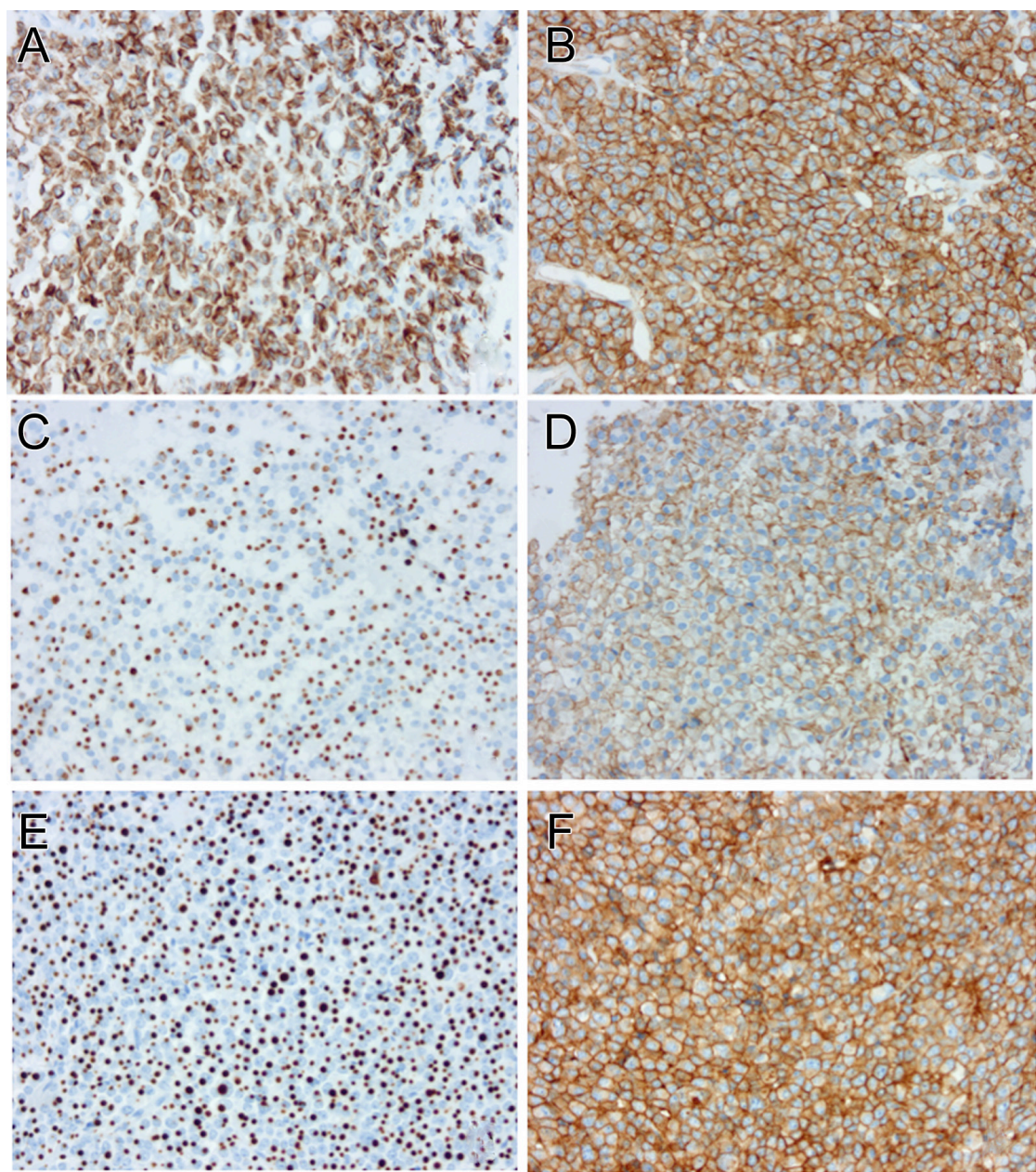

\section{Figure 3}

Examples of granulation and SSTR5 immunoexpression in 3 patients and correlation with the IGF-1 response to Pasireotide-LAR. Cytokeratin 18 immunohistochemistry (A, C and E, original magnification $\times 200$ ). Densely granulated adenomas show perinuclear distribution of cytokeratin 18. Conversely, 'fibrous bodies' are typical of sparsely granulated adenomas. SSTR5 immunohistochemistry ( $B, D$ and $F$, original magnification $\times 200$ ). Immunoexpression of SSTR5 is expressed using ImmunoReactive Score (IRS). (A and $B$ ) Densely granulated adenoma with a strong and diffuse immunoexpression of SSTR5 (IRS = 12) and poor response to Pasireotide-LAR (IGF-1 = 3.3 ULN). (C and D) Sparsely granulated adenoma with a moderate immunoexpression of SSTR5 (IRS = 6) and good response to Pasireotide-LAR (IGF-1 = 0.7 ULN). (E and F) Sparsely granulated adenoma with a strong and diffuse immunoexpression of SSTR5 (IRS = 12) and uncontrolled IGF-1 with Pasireotide-LAR (IGF-1 ULN = 1.8)
(Shimon et al. (12)). In our study, it was impossible to predict, using clinical data, the individual response to the switch to enable the selection of the best candidates. This heterogeneity may be partially explained by an acromegalic population with large variations in sensitivity to 1gSRL. Interestingly, it seems that patients receiving the lower dosage of PEG were more likely to respond to Pasireotide-LAR, possibly reflecting better 'baseline' sensitivity to $1 \mathrm{gSRL}$. This finding is similar to that of Muhammad et al (11) where the best IGF-1 control was obtained in patients that remained controlled prior to the switch despite a 50\% reduction in weekly PEG dosage.

In our study, patients with normalization of IGF-1 at the first evaluation was lower than the $73.3 \%$ rate reported in Muhammad et al (11), though their study did not specify the individual sensitivity to $1 \mathrm{gSRL}$. Our results accord more closely with the $67 \%$ rate of control obtained in nine patients previously receiving a combination therapy studied by Shimon et al (12). Sampling fluctuations across small cohorts as well as differences in study design, IGF-1 assays and normative data cohorts, may explain these variations but still indicate that a subset of acromegalic patients may benefit from a switch to Pasireotide-LAR. The small size of our cohort hampers the study of the Pasireotide-LAR dose/response relationship but it should be noted that some 'sensitive' individuals had IGF-1 levels within the lowest half of the normal range on a dose of $40 \mathrm{mg} / \mathrm{month}$ and may benefit from a reduced dosage to both improve metabolic tolerance of the drug while achieving acceptable control of the disease (12).

As was noted in previous trials $(9,10,11,12,17)$, impaired glycemic tolerance resulting from inhibition of insulin and incretin secretion (18), was the main drawback of Pasireotide-LAR treatment. The proportion of diabetic patients increased at the first evaluation, and introduction/intensification of antidiabetic treatment was required in 6/15 patients. Importantly, and as noted in the Paola study (10), diabetic patients, mainly those requiring pharmacological treatment and, to lesser degree patients with prediabetes, were more susceptible to the hyperglycemic effect of Pasireotide-LAR. Of note, patients required intensification of antidiabetic treatments

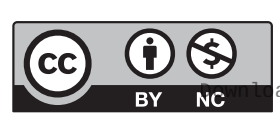

This work is licensed under a Creative Commons Attribution-NonCommercial 4.0 International License. ded from Bioscientifica.com at 04/26/2023 10:24:12AM 
regardless of the evolution of IGF-1 levels. This confirms that Pasireotide-LAR should be prescribed with caution in diabetic patients and should be associated with frequent monitoring of FBG in order to adapt and reconsider treatment. Importantly, none of the patients experienced acute ketoacidosis and, as reported previously, glucose tolerance was re-established after withdrawal of the drug (9).

Finally, 8/15 patients benefited from Pasireotide-LAR treatment with acceptable sustained control of IGF-1 at the expense of requiring an antidiabetic treatment in $2 / 15$. The remaining six patients had slight increases in HbA1c levels, the long-term impact of which is uncertain. Elsewhere, we have to evaluate glucose tolerance in patients who are well controlled with Pasireotide-LAR over the long-term since normalization of IGF-1 results in a decrease of lean mass and an increase in fat mass, both of which play an important role in glucose tolerance (19).

Contrary to PEG, Pasireotide-LAR may help to control tumor size and further reduction in adenoma volume has been noted in patients resistant to 1 gSRL $(10,20)$. We assessed the ability of Pasireotide-LAR to induce further shrinkage in our patients using tumor height measurements, a procedure that may be imprecise in comparison to tumor volume estimations. However, almost all patients in our study had been previously operated and had small-sized remnants which were sometimes difficult to precisely delineate, which may have masked small but definite shrinkage effects and that may render the antitumoral objective meaningless. We did not observe a shift in T2-hyperintensity in MRI scans, reflecting cystic degeneration or tumor cell necrosis that has recently been described in approximately $30 \%$ of patients after a switch to Pasireotide-LAR (20).

In an effort to identify biomarkers of treatment outcome and individualize the pharmacological treatment using a personalized approach (21), several studies have examined whether the in vivo efficacy of somatostatin analogs correlates with somatostatin receptor expression. Most of studies examined the correlation between immunohistochemical expression of SSTR2 using various scoring systems and the response to $1 \mathrm{gSRL}(21,22,23,24,25)$. Overall, some correlation was found, with the absence of membranous expression having a high negative predictive value $(21,22)$. The study of SSTR2 expression would have been irrelevant in our series since most patients were treated with 1gSRL before surgery, which has been shown to modify SSTR2 expression via receptor internalization (14).

Studies of histological factors predictive of the response to Pasireotide-LAR are rare. The expression of
SSTR5 is intuitively a good candidate since, contrary to 1 GSSA, Pasireotide is an affine ligand of the SSTR5 and since in vitro studies have shown that cultured adenomas with lower SSTR2/SSTR5 mRNA ratios responded better to Pasireotide (compared with octreotide) (23). To date, only two studies have been published. In a small cohort of 11 patients (24), a predictive role of membranous SSTR5 expression was suggested. Conversely, a recent study (26) in nine patients switched from a combination of 1gSRL+PEG to Pasireotide-LAR found the response positively correlated to SSTR2 IRS but not to SSTR5 IRS. We found no correlation between the SSTR5 IRS score, or the percentage of SSTR5-immunopositive cells, and the control of IGF-1 levels. Importantly, pre-surgical treatment with 1gSRL has been shown to have no effect on SSTR5 protein expression in somatotroph adenomas (23). The retrospective study design, the limited number of adenomas studied and the cellular heterogeneity of adenomas that were only partly removed may account for these discrepancies. Elsewhere, it is well accepted that a number of molecular characteristics are involved in the response to 1 GSSA (3) which is likely to be the same for the response to Pasireotide. We found a trend toward a better response of sparsely granulated adenomas compared to densely granulated ones, irrespective of SSTR5 expression. Although this trend comes from a limited number of patients, Iacovazzo et al also reported that differences in the response to Pasireotide correlated to cytokeratin expression levels (24). Elsewhere, the association between cytokeratin and SSTR5 expression remains controversial. As in our cohort, this was found to be negative in two large series using IHC analysis (27) and SSTR5 mRNA quantification (28), while Mayr et al. found membranous expression of SSTR5 exclusively in sparsely granulated adenomas (29). Further studies involving a larger number of patients with well-characterized in vivo responses to Pasireotide-LAR (ideally including patients fully resistant to 1 gSRL and variable responses to Pasireotide) and using standardized molecular tools to study multiple factors involved in the response to somatostatin analogs are needed to assess the value of this 'personalized' medicine approach in current clinical practice.

In conclusion, in our 'real-life' study, PasireotideLAR controlled IGF-1 levels over the long term with acceptable glucose tolerance in approximately half of the patients previously treated with a combination therapy. Close monitoring of blood glucose is important for all patients and should be reinforced in diabetic patients treated with oral hypoglycemic agents. Complementing recently published expert recommendations

(13), 
our results suggest that Pasireotide-LAR monotherapy can be a suitable alternative to combination therapies involving 1gSRL and cabergoline or PEG for the control of IGF-1 in a subset of acromegalic patients partly resistant to 1 GSSA. The intensity of SSTR5 expression and the granulation pattern of adenomas were of limited value for the prediction of Pasireotide-LAR effectiveness. Therefore, the identification of good candidates for Pasireotide-LAR remains to be determined and the classical trial-and-error approach to acromegaly treatment in each individual is still necessary. However, non-diabetic patients using relatively low PEGV dosages in association to 1gSRL are probably good candidates for such a switch.

\section{Declaration of interest}

The authors declare that there is no conflict of interest that could be perceived as prejudicing the impartiality of the research reported.

\section{Funding}

This work did not receive any specific grant from any funding agency in the public commercial, not-for-profit sector or industry.

\section{References}

1 Holdaway IM, Bolland MJ \& Gamble GD. A meta-analysis of the effect of lowering serum levels of GH and IGF-I on mortality in acromegaly. European Journal of Endocrinology 2008159 89-95. (https://doi.org/10.1530/EJE-08-0267)

2 Nomikos P, Buchfelder M \& Fahlbusch R. The outcome of surgery in 668 patients with acromegaly using current criteria of biochemical 'cure'. European Journal of Endocrinology 2005152 379-387. (https:// doi.org/10.1530/eje.1.01863)

3 Gadelha MR, Wildemberg LE, Bronstein MD, Gatto F \& Ferone D. Somatostatin receptor ligands in the treatment of acromegaly. Pituitary 201720 100-108. (https://doi.org/10.1007/s11102-017-0791-0)

4 Carmichael JD, Bonert VS, Nuño M, Ly D \& Melmed S. Acromegaly clinical trial methodology impact on reported biochemical efficacy rates of somatostatin receptor ligand treatments: a meta-analysis. Journal of Clinical Endocrinology and Metabolism 201499 1825-1833. (https://doi.org/10.1210/jc.2013-3757)

5 Chanson P, Brue T, Delemer B, Caron P, Borson-Chazot F, Zouater H \& Médecins de l'Étude ACROSTUDY. Pegvisomant treatment in patients with acromegaly in clinical practice: the French ACROSTUDY. Annales D'endocrinologie 201576 664-670. (https://doi. org/10.1016/j.ando.2015.10.003)

6 Neggers SJ, Franck SE, de Rooij FW, Dallenga AH, Poublon RM, Feelders RA, Janssen JA, Buchfelder M, Hofland LJ, Jørgensen JO, et al. Long-term efficacy and safety of pegvisomant in combination with long-acting somatostatin analogs in acromegaly. Journal of Clinical Endocrinology and Metabolism 201499 3644-3652. (https://doi.org/10.1210/jc.2014-2032)

7 Kuhn E \& Chanson P. Cabergoline in acromegaly. Pituitary 201720 121-128. (https://doi.org/10.1007/s11102-016-0782-6)

8 Strasburger CJ, Mattsson A, Wilton P, Aydin F, Hey-Hadavi J \& Biller BMK. Increasing frequency of combination medical therapy in the treatment of acromegaly with the GH receptor antagonist pegvisomant. European Journal of Endocrinology 2018178 321-329. (https://doi.org/10.1530/EJE-17-0996)
9 Colao A, Bronstein MD, Freda P, Gu F, Shen CC, Gadelha M, Fleseriu M, Lely AJ van der, Farrall AJ, Hermosillo Reséndiz K, et al. Pasireotide versus octreotide in acromegaly: a head-to-head superiority study. Journal of Clinical Endocrinology and Metabolism 201499 791-799. (https://doi.org/10.1210/jc.2013-2480)

10 Gadelha MR, Bronstein MD, Brue T, Coculescu M, Fleseriu M, Guitelman M, Pronin V, Raverot G, Shimon I, Lievre KK, et al. Pasireotide versus continued treatment with octreotide or lanreotide in patients with inadequately controlled acromegaly (PAOLA): a randomised, phase 3 trial. Lancet Diabetes and Endocrinology 20142 875-884. (https://doi.org/10.1016/S2213-8587(14)70169-X)

11 Muhammad A, Lely AJ van der, Delhanty PJD, Dallenga AHG, Haitsma IK, Janssen JAMJL \& Neggers SJCMM. Efficacy and safety of switching to pasireotide in patients with acromegaly controlled with pegvisomant and first-generation somatostatin analogues (PAPE study). Journal of Clinical Endocrinology and Metabolism 2018103 586-595. (https://doi.org/10.1210/jc.2017-02017)

12 Shimon I, Adnan Z, Gorshtein A, Baraf L, Saba Khazen N, Gershinsky M, Pauker Y, Abid A, Niven MJ, Shechner C, et al. Efficacy and safety of long-acting pasireotide in patients with somatostatinresistant acromegaly: a multicenter study. Endocrine 201862 448-455. (https://doi.org/10.1007/s12020-018-1690-5)

13 Coopmans EC, Muhammad A, Lely AJ van der, Janssen JAMJL \& Neggers SJCMM. How to position pasireotide LAR treatment in acromegaly. Journal of Clinical Endocrinology and Metabolism 2019104 1978-1988. (https://doi.org/10.1210/jc.2018-01979)

14 Casar-Borota O, Heck A, Schulz S, Nesland JM, Ramm-Pettersen J, Lekva T, Alafuzoff I \& Bollerslev J. Expression of SSTR2a, but not of SSTRs 1,3 , or 5 in somatotroph adenomas assessed by monoclonal antibodies was reduced by octreotide and correlated with the acute and long-term effects of octreotide. Journal of Clinical Endocrinology and Metabolism 201398 E1730-E1739. (https://doi.org/10.1210/ jc.2013-2145)

15 Obari A, Sano T, Ohyama K, Kudo E, Qian ZR, Yoneda A, Rayhan N, Mustafizur Rahman M \& Yamada S. Clinicopathological features of growth hormone-producing pituitary adenomas: difference among various types defined by cytokeratin distribution pattern including a transitional form. Endocrine Pathology 200819 82-91. (https://doi. org/10.1007/s12022-008-9029-z)

16 Chanson P, Arnoux A, Mavromati M, Brailly-Tabard S, Massart C, Young J, Piketty ML, Souberbielle JC \& VARIETE Investigators. Reference values for IGF-I serum concentrations: comparison of six immunoassays. Journal of Clinical Endocrinology and Metabolism 2016 101 3450-3458. (https://doi.org/10.1210/jc.2016-1257)

17 Bronstein MD, Fleseriu M, Neggers S, Colao A, Sheppard M, Gu F, Shen CC, Gadelha M, Farrall AJ, Hermosillo Reséndiz K, et al. Switching patients with acromegaly from octreotide to pasireotide improves biochemical control: crossover extension to a randomized, double-blind, Phase III study. BMC Endocrine Disorders 20161616. (https://doi.org/10.1186/s12902-016-0096-8)

18 Henry RR, Ciaraldi TP, Armstrong D, Burke P, Ligueros-Saylan M \& Mudaliar S. Hyperglycemia associated with pasireotide: results from a mechanistic study in healthy volunteers. Journal of Clinical Endocrinology and Metabolism 201398 3446-3453. (https://doi. org/10.1210/jc.2013-1771)

19 Bredella MA, Schorr M, Dichtel LE, Gerweck AV, Young BJ, Woodmansee WW, Swearingen B \& Miller KK. Body composition and ectopic lipid changes With biochemical control of acromegaly. Journal of Clinical Endocrinology and Metabolism 2017102 4218-4225. (https://doi.org/10.1210/jc.2017-01210)

20 Coopmans EC, Lely AJ van der, Schneiders JJ \& Neggers SJCMM. Potential antitumour activity of pasireotide on pituitary tumours in acromegaly. Lancet Diabetes and Endocrinology $20197425-426$. (https://doi.org/10.1016/S2213-8587(19)30113-5)

21 Kasuki L, Wildemberg LE \& Gadelha MR. Management of endocrine disease: personalized medicine in the treatment of acromegaly.

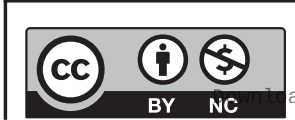

This work is licensed under a Creative Commons Attribution-NonCommercial 4.0 International License. ded from Bioscientifica.com at 04/26/2023 10:24:12AM 
European Journal of Endocrinology 2018178 R89-R100. (https://doi. org/10.1530/EJE-17-1006)

22 Marazuela M, Ramos-Leví AM, Borges de Souza P \& Zatelli MC. Is receptor profiling useful for predicting pituitary therapy? European Journal of Endocrinology 2018179 D15-D25. (https://doi.org/10.1530/ EJE-18-0549)

23 Gatto F, Feelders RA, Pas R van der, Kros JM, Waaijers M, SprijMooij D, Neggers SJCMM, Lelij AJ van der, Minuto F, Lamberts SWJ, et al. Immunoreactivity score using an anti-sst2A receptor monoclonal antibody strongly predicts the biochemical response to adjuvant treatment with somatostatin analogs in acromegaly. Journal of Clinical Endocrinology and Metabolism 201398 E66-E71. (https:// doi.org/10.1210/jc.2012-2609)

24 Iacovazzo D, Carlsen E, Lugli F, Chiloiro S, Piacentini S, Bianchi A, Giampietro A, Mormando M, Clear AJ, Doglietto F, et al. Factors predicting pasireotide responsiveness in somatotroph pituitary adenomas resistant to first-generation somatostatin analogues: an immunohistochemical study. European Journal of Endocrinology 2016 174 241-250. (https://doi.org/10.1530/EJE-15-0832)

25 Takei M, Suzuki M, Kajiya H, Ishii Y, Tahara S, Miyakoshi T, Egashira N, Takekoshi S, Sanno N, Teramoto A, et al. Immunohistochemical detection of somatostatin receptor (sstr) subtypes $2 \mathrm{~A}$ and 5 in pituitary adenoma from acromegalic patients: good correlation with preoperative response to octreotide. Endocrine
Pathology 200718 208-216. (https://doi.org/10.1007/s12022-0079004-0)

26 Muhammad A, Coopmans EC, Gatto F, Franck SE, Janssen JAMJL, Lely AJ van der, Hofland LJ \& Neggers SJCMM. Pasireotide responsiveness in acromegaly is mainly driven by somatostatin receptor subtype 2 expression. Journal of Clinical Endocrinology and Metabolism 2019104 915-924. (https://doi.org/10.1210/jc.201801524)

27 Chinezu L, Vasiljevic A, Jouanneau E, François P, Borda A, Trouillas J \& Raverot G. Expression of somatostatin receptors, SSTR2A and SSTR5, in 108 endocrine pituitary tumors using immunohistochemical detection with new specific monoclonal antibodies. Human Pathology 201445 71-77. (https://doi. org/10.1016/j.humpath.2013.08.007)

28 Kato M, Inoshita N, Sugiyama T, Tani Y, Shichiri M, Sano T, Yamada S \& Hirata Y. Differential expression of genes related to drug responsiveness between sparsely and densely granulated somatotroph adenomas. Endocrine Journal 201259 221-228. (https://doi.org/10.1507/endocrj.ej11-0177)

29 Mayr B, Buslei R, Theodoropoulou M, Stalla GK, Buchfelder M \& Schöfl C. Molecular and functional properties of densely and sparsely granulated GH-producing pituitary adenomas. European Journal of Endocrinology 2013169 391-400. (https://doi.org/10.1530/ EJE-13-0134)

Received in final form 10 September 2019

Accepted 13 September 2019

Accepted Preprint published online 13 September 2019 https://ec.bioscientifica.com

https://doi.org/10.1530/EC-19-0332 (c) 2019 The authors Published by Bioscientifica Ltd
This work is licensed under a Creative Commons Attribution-NonCommercial 4.0 International License. ded from Bioscientifica.com at 04/26/2023 10:24:12AM 